\title{
Prevalence of cardiovascular risk factors among workers at a private tertiary center in Angola
}

This article was published in the following Dove Press journal:

Vascular Health and Risk Management

I4 December 2016

Number of times this article has been viewed

\author{
Feliciano Chanana Paquissi' \\ Valdano Manuel $^{2}$ \\ Ana Manuel ${ }^{2}$ \\ Guiomar Lote Mateus' \\ Bruna David ${ }^{2}$ \\ Gertrudes Béu ${ }^{3}$ \\ Anselmo Castela ${ }^{3}$ \\ 'Department of Medicine, ${ }^{2}$ Cardio- \\ Thoracic Center, ${ }^{3}$ Service of \\ Endocrinology, Department of \\ Medicine, Clínica Girassol, Luanda, \\ Angola
}

Background: The burden of cardiovascular diseases (CVD) is increasing in most countries of sub-Saharan Africa. However, as there is a scarcity of data, little is known about CVD in Angola. This study aimed to determine the prevalence of prehypertension, hypertension, prediabetes, diabetes, overweight, and obesity among workers at a private tertiary center in Angola.

Methods: A cross-sectional study was conducted among 781 workers of Clínica Girassol, a tertiary health care center in Angola, during the month of November 2013. Demographic, anthropometric, and clinical variables were analyzed.

Results: Of the 781 participants studied, $50.44 \%$ were males and $78.11 \%$ were under 40 years old. The prevalence of hypertension and prehypertension was $17.93 \%$ (95\% confidence interval [CI]: 15.24\%-20.74\%) and 54.03\% (95\% CI: 50.58\%-57.62\%), respectively. Among hypertensive subjects, $83.57 \%$ (117) were unaware of the diagnosis. Hypertension was associated with age ( $\geq 40$ years) (odds ratio [OR]: $6.21 ; 95 \%$ CI: 4.18-9.24; $P<0.001$ ) and with overweight and obesity (OR: 2.32 ; 95\% CI: $1.56-3.44 ; P<0.001$ ). The prevalence of diabetes and prediabetes was $2.69 \%$ (95\% CI: $1.54 \%-3.97 \%$ ) and 7.94\% (95\% CI: 6.02\%-9.99\%), respectively. The prevalence of overweight was $34.44 \%$ (95\% CI: $31.11 \%-37.90 \%)$ and $19.85 \%$ (95\% CI: $17.03 \%-22.79 \%$ ) for obesity. There was an association between overweight and obesity and the female sex (OR: $1.71 ; 95 \%$ CI: $1.29-2.28 ; P<0.001$ ). The prevalence of family history of CVD, smoking, and alcoholism was $52.24 \%, 4.87 \%$, and $45.33 \%$, respectively.

Conclusion: There was a high prevalence of cardiovascular risk factors in apparently healthy workers at the private tertiary center in Angola.

Keywords: risk factors, hypertension, prehypertension, diabetes mellitus, obesity, Angola

\section{Introduction}

Cardiovascular diseases (CVDs) are the leading cause of morbidity and mortality worldwide. ${ }^{1,2}$ About 17.3 million people died from CVD in 2008. ${ }^{2}$ In recent years, some studies have demonstrated that CVD mortality increased in developing countries, ${ }^{2,3}$ and these countries have the greatest absolute number of people with hypertension the main risk factor for CVD. Additionally projections point to a $60 \%$ increase in the prevalence of hypertension in developing countries during the period of 2000-2025.

In sub-Saharan Africa, the prevalence of CVD has increased in the last 20 years. ${ }^{5,6}$ From 1990 to 2010, the three risk factors that showed the highest perceptual increase in the region were the body mass index (BMI), blood pressure (BP), and blood sugar changes. $^{7}$ The deaths from CVD in this region presented a parallel increase; and it has been shown that in sub-Saharan Africa deaths due to CVD occur in younger people compared to the rest of the world. ${ }^{3,8}$ However, the health system of most countries in
Paquissi

Department of Medicine, Clínica

Girassol, Comandante Gika 225, Luanda,

Angola

Tel +55 II95702 1718

Email fepaquissi@gmail.com 
the region do not have the preparedness to respond to this new reality. ${ }^{9-11}$ In addition, sub-Saharan Africa remains the region of the world where there is scarcity of data on CVD. ${ }^{8,12,13}$

In Angola, it was estimated that approximately 27,000 people died from CVD and diabetes mellitus (DM) during 2012. ${ }^{14}$ Little is known about the prevalence of cardiovascular risk factors in the general population. In the few available studies, the prevalence of hypertension ranged from $23 \%$ to $45.2 \% ;^{15-17}$ and overweight and obesity $29.3 \%$ and $19.6 \%$, respectively. ${ }^{17}$ The prevalence of DM was $2.8 \%$ and $5.7 \%$ in urban and rural population, respectively. ${ }^{17,18}$

Economic changes, industrialization, and the urbanization, which Angola has experienced, are associated with the development of CVD. ${ }^{19,20}$ The interaction of these factors with other determinants, such as the low level of education, ethnic factors, and health system failures, can increase the impact of CVD on public health; ${ }^{11,14}$ whereas older problems such as infectious, maternal, and perinatal diseases still represent an important burden (leading to mortality) in the country. ${ }^{8,14,21}$

This study aimed to determine the prevalence of the main cardiovascular risk factors among workers of a private tertiary center in Angola.

\section{Materials and methods Design, location, and population of the study}

A cross-sectional study was conducted among 781 workers $(52.06 \%$ of 1,500$)$ of Clínica Girassol during the month of November 2013. The Clínica Girassol is a private tertiary health care center of the Sonangol group, located in Luanda, Angola, with 1,500 workers, aged between 18 and 65 years old (about 75\% under the age of 40 years), of different occupational categories, mostly nurses and physicians.

All subjects at work during the month of November 2013 were invited to participate and were included after a written informed consent form was signed.

\section{Study variables}

The assessment included a questionnaire, used by previously trained interviewers, with close-ended questions about age, sex, personal medical history, family history of CVD, smoking, and alcoholism. This was followed by the measurement of continuous variables of the study (such as weight, height, capillary glycemia, and BP). We took hypertension, DM, overweight, and obesity as dependent variables and the others as independent variables.

Weight was measured with an electronic digital Seca ${ }^{\circledR}$ scale (Seca, Hamburg, Germany) with a capacity of up to
$150 \mathrm{~kg}$ and precision of $100 \mathrm{~g}$. The scale was calibrated and certified by the manufacturer, and checked regularly by the clinical engineering service of the institution. Height was measured in centimeters using a stadiometer included in the scale, with maximum extension of $200 \mathrm{~cm}$ and precision of $0.1 \mathrm{~cm}$. The BMI was calculated as the weight in kilograms divided by height in square meters $(\mathrm{BMI}=$ weight $[\mathrm{kg}] \div$ height $\left[\mathrm{m}^{2}\right]$ ). Based on the BMI, the population was categorized into subgroups as follow: low weight $\left(<18.5 \mathrm{~kg} / \mathrm{m}^{2}\right)$, ideal weight (18.5-24.9 kg/m²), overweight $\left(25-29.9 \mathrm{~kg} / \mathrm{m}^{2}\right)$, and obese $\left(\geq 30 \mathrm{~kg} / \mathrm{m}^{2}\right)$ using the World Health Organization classification criteria. ${ }^{22}$ Obesity was classified as Grade I (BMI $\geq 30.00-34.99$ ), Grade II (BMI $\geq 35.00-39.99$ ), and Grade III (BMI $\geq 40.00) .{ }^{22}$

The capillary blood sugar was measured with a Contour Next ${ }^{\circledR}$ (Bayer Vital, Leverkusen, Germany) instrument. Based on the time from the last food intake, capillary blood sugar was considered fasting glucose (if $>8$ hours after last meal) or capillary random glucose (if $<8$ hours after last meal). We considered DM for fasting blood sugar $\geq 126 \mathrm{mg} / \mathrm{dL}$, or a random blood sugar $\geq 200 \mathrm{mg} / \mathrm{dL}$, or previous diagnosis of DM with the use of medication, according to the guidelines of American Diabetes Association. ${ }^{23}$ We considered impaired fasting glucose if fasting glucose $\geq 100 \mathrm{mg} / \mathrm{dL}$, but $<126 \mathrm{mg} / \mathrm{dL}$; and impaired glucose tolerance if random capillary blood glucose $\geq 140 \mathrm{mg} / \mathrm{dL}$, but $<200 \mathrm{mg} / \mathrm{dL}$. Impaired fasting glucose and impaired glucose tolerance were included in a single category of prediabetes. ${ }^{23,24}$

BP was assessed according to Joint National Committee (JNC)-VII guidelines ${ }^{25}$ by using an auscultatory method with an aneroid sphygmomanometer certified by the manufacturer, and the instrument was checked regularly by the clinical engineering service. BP was measured using an appropriately sized cuff for brachial circumference. The measurement was performed on the right arm, after a rest of at least 5 minutes, and in a calm environment. Based on the value of BP, the population was categorized into three subgroups: normotensives (BP <120/80 mmHg); prehypertensives (systolic BP [SBP] from 120 to $139 \mathrm{mmHg}$ and/or diastolic BP [DBP] from 80 to $89 \mathrm{mmHg}$ ); and hypertensives ( $\mathrm{SBP} \geq 140 \mathrm{mmHg}$ and/or DBP $\geq 90 \mathrm{mmHg}$ ). ${ }^{25}$ We also considered as hypertensive all those with a previous diagnosis in use of medication, regardless of BP levels.

\section{Statistical analysis}

The software Epi info version 7.1.4 (Centers for Disease Control and Prevention, Atlanta, GA, USA) was used as a database. Demographic characteristics of the sample were analyzed, and we calculated the prevalence of hypertension, 
prehypertension, overweight, obesity, prediabetes, and DM in the general sample and also specifically by age and sex. To estimate the association between independent and dependent variables, we used the odds ratio (OR) as a risk measure, with the corresponding 95\% confidence interval (CI). Frequency comparison between groups was performed by $\chi^{2}$, and, a $P$-value $<0.05$ was considered statistically significant. The analysis was performed using "OpenEpi", an online software, version $3.03(\mathrm{CDC}){ }^{26}$

\section{Ethical implications}

The study was approved by the Teaching Postgraduate, and Research Office, which is the committee responsible for ethical issues in the Clínica Girassol. The workers were free to choose to participate in the study or not, and they were included only after written informed consent was signed. The researchers guaranteed the preservation of participants' confidential data, strict and impartial analysis of the results, and the participants diagnosed as diabetic or hypertensive were advised to have a clinical follow-up.

\section{Results}

A total of 781 workers were evaluated, and their demographic characteristics are presented in Table 1 . There was no significant difference between sexes, most workers (78.11\%) were aged under 40 years, and were Black Africans.

Regarding BP 28.04\% $(n=219$; 95\% CI: $24.84 \%-$ $31.37 \%)$ of participants had normal BP, $54.03 \%(n=422$; 95\% CI: 50.58\%-57.62\%) had prehypertension, and $17.93 \%$ ( $n=140 ; 95 \%$ CI: 15.24\%-20.74\%) had hypertension (Figure 1). Among hypertensive subjects, 83.57\% (117) were unaware of their BP status until the time of this evaluation. Hypertension was associated with age ( $\geq 40$ years) (OR: 6.21; 95\% CI: 4.18-9.24; $P<0.001)$ and with overweight and obesity (OR: 2.32; 95\% CI: $1.56-3.44 ; P<0.001$ ), but

Table I Demographic characteristics of the study population

\begin{tabular}{lll}
\hline Characteristic & Absolute frequency & $\%$ \\
\hline Age (years) & 1 & \\
$<20$ & 280 & 0.1 \\
$20-30$ & 330 & 35.9 \\
$31-40$ & $12 I$ & 42.3 \\
$4 I-50$ & $4 I$ & 15.5 \\
$5 I-60$ & 8 & 5.2 \\
$>60$ & $78 I$ & 1.0 \\
Total & & 100 \\
Sex & 394 & \\
Male & 387 & 50.4 \\
Female & & 49.6 \\
\hline
\end{tabular}

Note: Clínica Girassol, Luanda, Angola, November 2013 (n=78I). there was no significant difference between men and women (19.29\% vs $\left.16.28 \% ; \chi^{2}=1.01 ; P=0.27\right)$. In the sample, $89.37 \%(\mathrm{n}=698 ; 95 \% \mathrm{CI}: 87.20 \%-91.68 \%)$ had normal blood sugar; and the prevalence of DM and prediabetes was $2.69 \%(n=21 ; 95 \%$ CI: $1.54 \%-3.97 \%)$ and $7.94 \%(n=62$; 95\% CI: 6.02\%-9.99\%), respectively (Figure 2). Among diabetic patients, $90.48 \%$ were under treatment and $9.52 \%$ were unaware of the diagnosis. DM was associated with age ( $\geq 40$ years) (OR: 4.13; 95\% CI: $1.72-9.89 ; P<0.001$ ), and individuals who were overweight and obese presented a no significant trend to higher prevalence of DM than those with ideal body weight $\left(3.302 \%\right.$ vs $\left.1.961 \% ; \chi^{2}=1.33 ; P=0.35\right)$. Regarding weight, $3.07 \%(\mathrm{n}=24 ; 95 \% \mathrm{CI}: 1.92 \%-4.35 \%)$ of participants were underweight, $34.44 \%(n=269 ; 95 \% \mathrm{CI}$ : $31.11 \%-37.90 \%)$ overweight, and 19.85\% $(n=155 ; 95 \%$ CI: 17.03\%-22.79\%) were obese (Figure 3). Among 155 workers with obesity, 77.42\% had Grade I, 16.13\% Grade II, and 6.45\% Grade III (Figure 4). Overweight and obesity

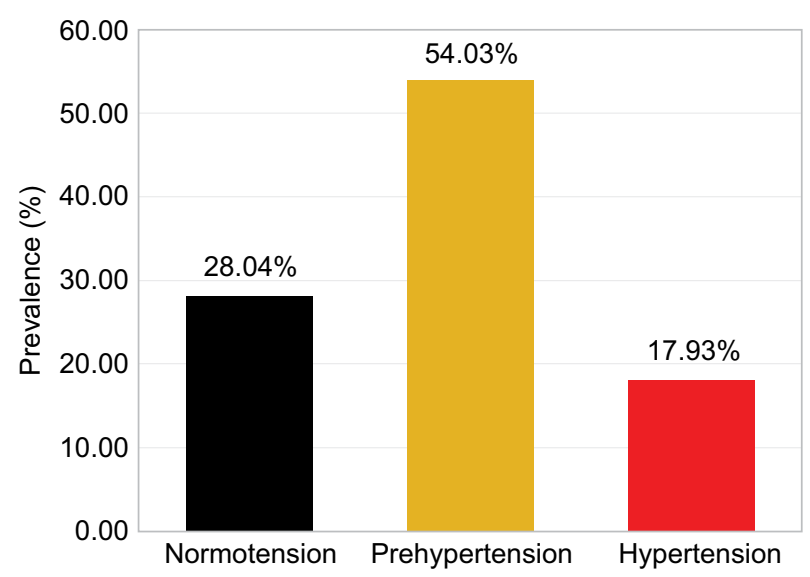

Figure I Blood pressure distribution among the study population. Note: Clínica Girassol, Luanda, Angola, November 2013 ( $n=781$ ).

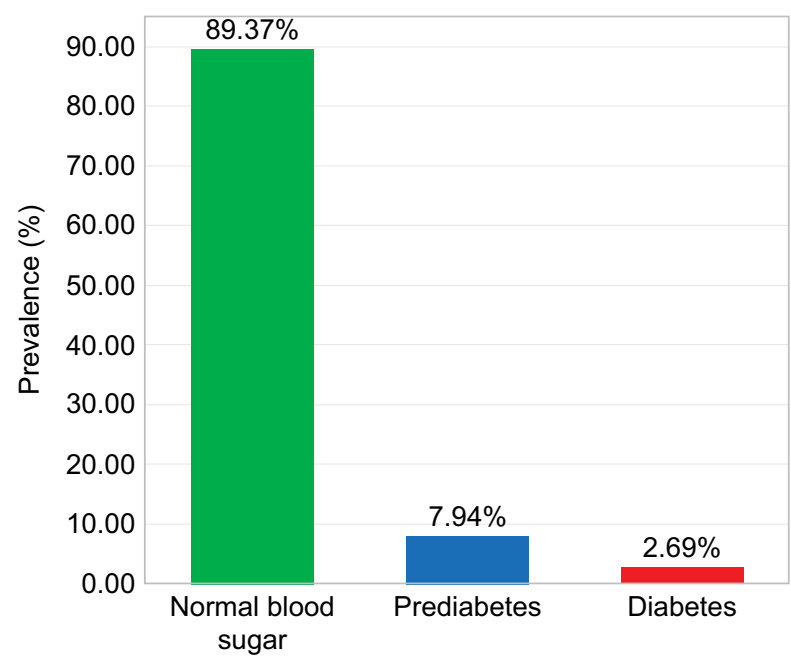

Figure 2 Prevalence of diabetes and prediabetes in study population. Note: Clínica Girassol, Luanda, Angola, November 2013 ( $n=781$ ). 
was higher in women than men $\left(60.98 \%\right.$ vs $47.72 \% ; \chi^{2}$ $=13.32 ; P<0.001)$.

Family history of CVD, active smoking, and alcoholic beverage consumption was reported by $52.24 \%$ ( $n=408 ; 95 \%$ CI: $48.78 \%-55.82 \%), 4.87 \%(n=38 ; 95 \%$ CI: $2.05 \%-6.53 \%)$, and $45.33 \%$ ( $n=354 ; 95 \% \mathrm{CI}: 41.87 \%-48.91 \%)$ of workers, respectively. Table 2 presents the summary of the association between independent and dependent variables, in univariate analysis.

\section{Discussion}

\section{Blood pressure}

In this study, we found a prehypertension prevalence of $54.03 \%$, which is considerably high taking into account the average age of the study population. However, it is in concordance with other studies conducted among African populations, in Nigeria and Egypt, where the prevalence was

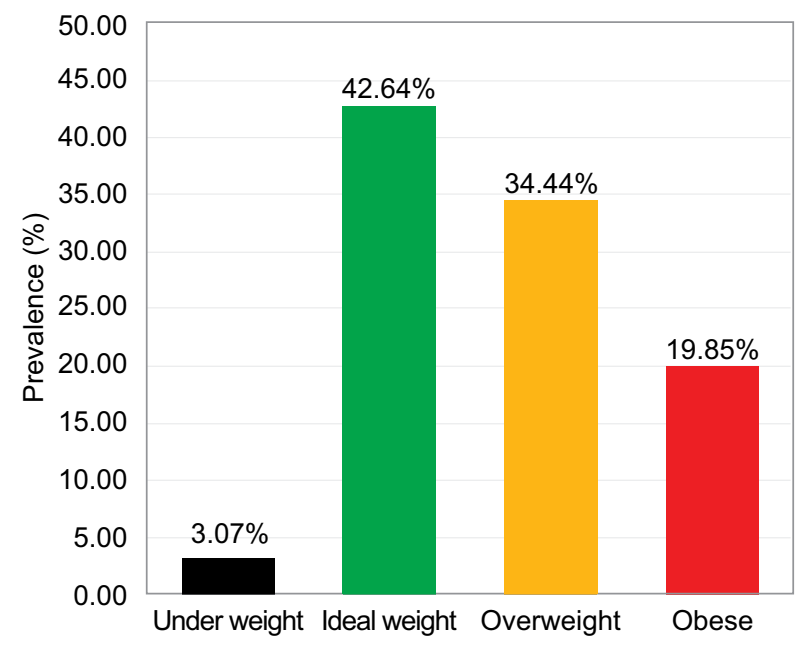

Figure 3 Distribution of the study population according to BMI. Note: Clínica Girassol, Luanda, Angola, November 2013 ( $n=781$ ). Abbreviation: BMI, body mass index.

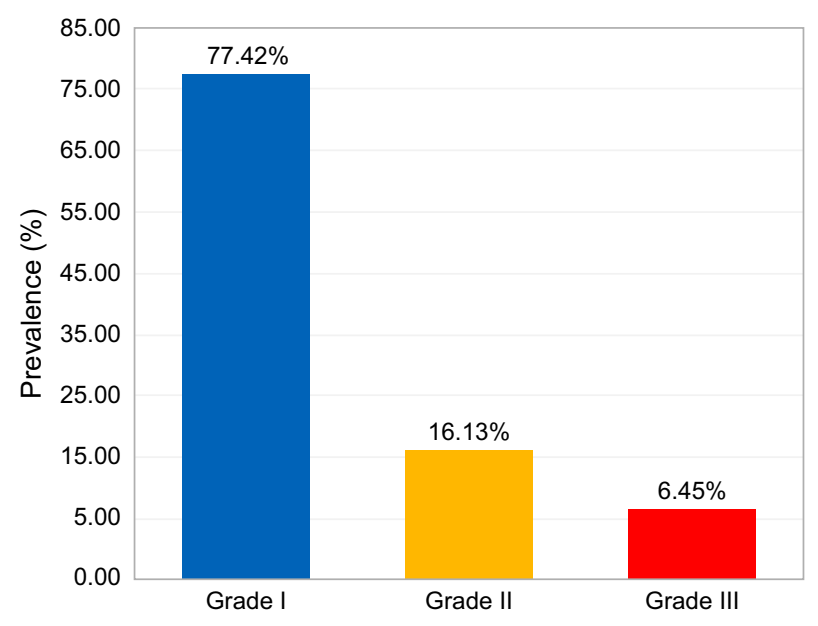

Figure 4 Distribution of obese subjects according to the grade. Grade I (BMI $\geq 30.00-34.99$ ), grade II (BMI $\geq 35.00-39.99)$, and grade III (BMI $\geq 40.00)$.

Note: Clínica Girassol, Luanda, Angola, November $2013(\mathrm{n}=155)$.
Table 2 Univariate analysis of the association between independent and dependent variables

\begin{tabular}{llll}
\hline Factor & OR & $\mathbf{9 5 \% ~ C l}$ & P-value \\
\hline Hypertension & & & \\
Age $(\geq 40$ vs $<40$ years) & 6.21 & $4.18-9.24$ & $<\mathbf{0 . 0 0 1}$ \\
$\quad$ Overweight and obesity & 2.32 & $1.56-3.44$ & $<\mathbf{0 . 0 0 1}$ \\
$\quad$ Sex (male vs female) & 1.23 & $0.85-1.78$ & 0.27 \\
Diabetes & & & \\
$\quad$ Age ( $\geq 40$ vs $<40$ years) & 4.13 & $1.72-9.89$ & $<\mathbf{0 . 0 0 1}$ \\
$\quad$ Overweight and obesity & 1.71 & $0.68-4.28$ & 0.35 \\
Overweight and obesity & & & \\
$\quad$ Sex (female vs male) & 1.71 & $1.29-2.28$ & $<\mathbf{0 . 0 0 1}$ \\
\hline
\end{tabular}

Note: Workers, Clínica Girassol, Luanda, Angola, 2013 ( $n=781)$. Values in bold are statistically significant.

Abbreviations: OR, odds ratio; $\mathrm{Cl}$, confidence interval.

$58.7 \%$ and $57.2 \%$, respectively. ${ }^{27,28}$ This is the first study that evaluated prehypertension in Angola. The high prevalence we found is of paramount importance since the rate of progression from prehypertension to hypertension in follow-up studies was $29 \%$ (in 4.1 years) in a Jamaican cohort ${ }^{29}$ and $30.4 \%$ in 3 years of follow-up among postmenopausal women, ${ }^{30}$ and can reach a high progression rate up to $13.9 \%$ per year. ${ }^{31}$ In addition, we highlight the value of racial factor and BMI, because the Black race was found to be a predictor of faster progression $^{32}$ as well as a high BMI. ${ }^{33}$

On the other hand, regardless of progression, prehypertension is itself a risk factor for coronary artery disease, end-stage renal disease, and cerebrovascular events. ${ }^{34,35}$ In a meta-analysis of 20 cohort studies with 1,129,098 participants, prehypertension significantly increased mortality due to stroke. ${ }^{36}$ We emphasize that in African populations, stroke occurs earlier than in rest of the world and is the leading cause of cardiovascular mortality. ${ }^{8}$ So, a high prevalence, as we found, associated with low awareness and control, may be one of the factors that contribute to this finding.

The prevalence of hypertension was $17.93 \%$, which is nearly the average (16.2\%) prevalence of this condition in the region ${ }^{6,37}$ and in line with that found in a study in Ethiopia (another country in this region). ${ }^{38}$ However, it is relatively lower compared to that found in other studies carried out in Angola ${ }^{15-18}$ and some other countries in the region such as South Africa, Nigeria, and Uganda. ${ }^{27,39,40}$ This difference might be due to the younger population in this study $(78.11 \%$ of them $<40$ years) compared to the other studies. The difference in prevalence compared to other countries, like South Africa, may be due to the actual differences in the prevalence of risk factors for hypertension. ${ }^{39}$ There was no statistically significant difference between sexes in the occurrence of hypertension, which is in line with the results reported by other studies carried out in the region. ${ }^{12,41}$ 
Among hypertensive subjects, $83.57 \%$ were unaware of their status, nearly $78.4 \%$ found in another study conducted in northern Angola, where among those who were aware, only $13.9 \%$ were under pharmacological treatment and of these, only about one-third had their BP controlled. ${ }^{16}$

\section{Diabetes mellitus and prediabetes}

The prevalence of DM (2.69\%) was close to $2.9 \%$, which is the rate estimated for the country's population by the International Federation of Diabetes for the year $2013 ;{ }^{42}$ but relatively lower than that found in previous studies in the country, ${ }^{17,18}$ and in neighboring countries $(3.5 \%$ in southern Congo and $3.9 \%$ in South Africa). ${ }^{43,44}$ The occurrence of DM was significantly associated with age $>40$ years, which is in line with the results obtained from other studies. ${ }^{18,43}$ The association with BMI was not statistically significant.

The prevalence of prediabetes (7.94\%) was similar to that found in a study in Uganda. ${ }^{45}$ It is worth remembering that the rate of progression from prediabetes to $\mathrm{DM}$ is $6.8 \%$ per year. ${ }^{46} \mathrm{And}$ among individuals categorized as prediabetic by both criteria ( $\mathrm{HbA}_{1 \mathrm{c}}$ and fasting glucose), the cumulative risk of developing DM was $100 \%$ in a 5.6 years' follow-up study. ${ }^{47}$ In addition, prediabetes is itself associated with increased risk of cardiovascular mortality. ${ }^{48}$

\section{Overweight and obesity}

In relation to BMI, the combined prevalence of overweight and obesity was $54.29 \%$, which is relatively higher than that of previous studies, ${ }^{15,17}$ suggesting a trend to increase in prevalence of weight-related problems. This is reinforced when we observe that in a study conducted approximately 10 years ago the prevalence of obesity was significantly lower than in the current ( $3.2 \%$ vs $20 \%$ ), and there were no individuals with Grade III obesity. ${ }^{15}$ In this study, overweight and obesity were higher in women, which is in accordance with another study in the country, ${ }^{17}$ and the global trend; $; 9$ and was associated with a higher rate of high BP, as is traditionally reported..$^{50}$

\section{Other cardiovascular risk factors}

In relation to other cardiovascular risk factors, the prevalence of smoking was lower ( $4.9 \%$ vs $7.2 \%)$ than that found among public workers in Luanda ${ }^{17}$ and below the $9.0 \%$ estimated for the population of the country for the year $2012 .{ }^{51}$ The prevalence was higher in men than in women, as found in other countries in the region..$^{52,53}$ The prevalence of alcohol consumption was in line with that of another study. ${ }^{15}$ Positive family history of CVD was reported by $52.24 \%$ of participants.

\section{Conclusion}

The present study shows a high prevalence of cardiovascular risk factors in apparently healthy workers. This exposes the need for more studies to better measure the magnitude of the situation and guide the response planning to this problem.

\section{Limitations}

The main limitation of this study is the use of capillary blood glucose, as well as the consideration of glucose intolerance by random capillary blood glucose (and not 2-hour post $75 \mathrm{~g}$ of glucose). These options were adopted because they are more feasible approaches in resource-limited countries. Another limitation is related to the representativeness of the population. However, this is one among few existing studies in the country about the prevalence of cardiovascular risk factor among specific groups, and we believe that this study will serve as a starting point for national studies, which are now very necessary.

\section{Acknowledgment}

The authors sincerely acknowledge the hospital board and workers of the Clínica Girassol, Luanda, Angola.

\section{Author contributions}

FCP and VM analyzed the data and wrote the paper. All authors contributed to conception and design of the study, performed the data collection, revised, and approved the final version of the manuscript.

\section{Disclosure}

The authors report no conflicts of interest in this work.

\section{References}

1. Lozano R, Naghavi M, Foreman K, et al. Global and regional mortality from 235 causes of death for 20 age groups in 1990 and 2010: a systematic analysis for the Global Burden of Disease Study 2010. Lancet. 2012;380(9859):2095-2128.

2. World Health Organization. Global Status Report on Noncommunicable Diseases 2010. Geneva: World Health Organization; 2010.

3. Vedanthan R, Seligman B, Fuster V. Global perspective on acute coronary syndrome: a burden on the young and poor. Circ Res. 2014;114(12):1959-1975.

4. Kearney PM, Whelton M, Reynolds K, Muntner P, Whelton PK, He J. Global burden of hypertension: analysis of worldwide data. Lancet. 2005;365(9455):217-223.

5. Adeloye D, Basquill C. Estimating the prevalence and awareness rates of hypertension in Africa: a systematic analysis. PLoS One. 2014;9(8):e104300.

6. Twagirumukiza M, De Bacquer D, Kips JG, de Backer G, Stichele RV, Van Bortel LM. Current and projected prevalence of arterial hypertension in sub-Saharan Africa by sex, age and habitat: an estimate from population studies. J Hypertens. 2011;29(7):1243-1252.

7. Mensah GA. Descriptive epidemiology of cardiovascular risk factors and diabetes in sub-saharan Africa. Prog Cardiovasc Dis. 2013;56(3):240-250. 
8. Moran A, Forouzanfar M, Sampson U, Chugh S, Feigin V, Mensah G. The epidemiology of cardiovascular diseases in sub-saharan Africa: the global burden of diseases, injuries and risk factors 2010 study. Prog Cardiovasc Dis. 2013;56(3):234-239.

9. Kengne AP, Mayosi BM. Readiness of the primary care system for non-communicable diseases in sub-Saharan Africa. Lancet Glob Heal. 2014;2(5):e247-e248.

10. Costa Mendes IA, Marchi-Alves LM, Mazzo A, et al. Healthcare context and nursing workforce in a main city of Angola. Int Nurs Rev. 2013;60(1):37-44.

11. Cameron A, Roubos I, Ewen M, Mantel-Teeuwisse AK, Leufkens HG, Laing RO. Differences in the availability of medicines for chronic and acute conditions in the public and private sectors of developing countries. Bull World Health Organ. 2011;89(6):412-421.

12. Dalal S, Beunza JJ, Volmink J, et al. Non-communicable diseases in sub-Saharan Africa: what we know now. Int J Epidemiol. 2011;40(4): 885-901.

13. Hertz JT, Reardon JM, Rodrigues CG, et al. Acute myocardial infarction in sub-Saharan Africa: the need for data. PLoS One. 2014;9(5):e96688.

14. WHO. Noncommunicable Diseases Country Profiles 2014 - UK. Geneva: World Health Organization; 2014. Available from: http://www. who.int/nmh/countries/gbr_en.pdf?ua=1. Accessed November 8, 2014.

15. Simão M, Hayashida M, dos Santos CB, Cesarino EJ, Nogueira MS. Hypertension among undergraduate students from Lubango, Angola. Rev Lat Am Enfermagem. 2008;16(4):672-678.

16. Pires JE, Sebastião YV, Langa AJ, Nery SV. Hypertension in Northern Angola: prevalence, associated factors, awareness, treatment and control. BMC Public Health. 2013;13(1):90.

17. Capingana DP, Magalhães P, Silva AB, et al. Prevalence of cardiovascular risk factors and socioeconomic level among public-sector workers in Angola. BMC Public Health. 2013;13(1):732.

18. Evaristo-Neto AD, Foss-Freitas MC, Foss MC. Prevalence of diabetes mellitus and impaired glucose tolerance in a rural community of Angola. Diabetology \& metabolic syndrome. 2010;2(1):63.

19. Vorster HH. The emergence of cardiovascular disease during urbanisation of Africans. Public Health Nutr. 2002;5(1A):239-243.

20. Allender S, Lacey B, Webster P, et al. Level of urbanization and noncommunicable disease risk factors in Tamil Nadu, India. Bull World Health Organ. 2010;88(4):297-304.

21. Lim SS, Vos T, Flaxman AD, et al. A comparative risk assessment of burden of disease and injury attributable to 67 risk factors and risk factor clusters in 21 regions, 1990-2010: a systematic analysis for the Global Burden of Disease Study 2010. Lancet. 2012;380(9859):2224-2260.

22. WHO. Obesity: preventing and managing the global epidemic. Report of a WHO consultation. World Health Organ Tech Rep Ser. 2000;894:i-xii, 1-253. Available from: http://www.ncbi.nlm.nih.gov/ pubmed/11234459. Accessed July 16, 2014.

23. American Diabetes Association. Standards of medical care in diabetes - 2010. Diabetes Care. 2010;33(Suppl 1):S11-S61.

24. World Health Organization. Definition and Diagnosis of Diabetes Mellitus and Intermediate Hyperglycaemia. Geneva, Switzerland: World Health Organization; 2006. Available from: http://apps.who.int//iris/ handle/10665/43588.

25. Chobanian AV, Bakris GL, Black HR, et al. Seventh report of the Joint National Committee on Prevention, Detection, Evaluation, and Treatment of High Blood Pressure. Hypertension. 2003;42(6):1206-1252.

26. Dean A, Sullivan K, Soe M. OpenEpi: Open Source Epidemiologic Statistics for Public Health, 2011. Available from: www.OpenEpi.com. Accessed November 8, 2014.

27. Isezuo SA, Sabir AA, Ohwovorilole AE, Fasanmade OA. Prevalence, associated factors and relationship between prehypertension and hypertension: a study of two ethnic African populations in Northern Nigeria. J Hum Hypertens. 2011;25(4):224-230.

28. Ahmed N, Arafa S, Ez-elarab HS. Epidemiology of prehypertension and hypertension among egyptian adults introduction. Egypt $J$ Community Med. 2011;29(1):1-18. Available from: https://scholar. google.com.br/scholar?cluster $=14268895851298319893 \&$ hl $=$ en \&as_sdt $=2005 \&$ sciodt $=0,5$. Accessed November 8, 2014.
29. Ferguson TS, Younger N, Tulloch-Reid MK, et al. Progression from prehypertension to hypertension in a Jamaican cohort: incident hypertension and its predictors. West Indian Med J. 2010;59(5): 486-493.

30. Zambrana RE, López L, Dinwiddie GY, et al. Prevalence and incident prehypertension and hypertension in postmenopausal hispanic women: results from the women's health initiative. Am J Hypertens. 2014;27(3):372-381

31. Zheng L, Sun Z, Zhang X, et al. Predictors of progression from prehypertension to hypertension among rural Chinese adults: results from Liaoning Province. Eur J Cardiovasc Prev Rehabil. 2010;17(2): 217-222.

32. Hsia J, Margolis KL, Eaton CB, et al. Prehypertension and cardiovascular disease risk in the women's health initiative. Circulation. 2007;115(7):855-860.

33. Tomiyama H, Matsumoto C, Yamada J, et al. Predictors of progression from prehypertension to hypertension in Japanese men. Am J Hypertens. 2009;22(6):630-636.

34. Huang Y, Wang S, Cai X, et al. Prehypertension and incidence of cardiovascular disease: a meta-analysis. BMC Med. 2013;11(1):177.

35. Huang Y, Cai X, Zhang J, et al. Prehypertension and incidence of ESRD: a systematic review and meta-analysis. Am J Kidney Dis. 2014; 63(1):76-83.

36. Huang Y, Su L, Cai X, et al. Association of all-cause and cardiovascular mortality with prehypertension: a meta-analysis. Am Heart $J$. 2014;167(2):160-168.e1.

37. Ogah OS, Rayner BL. Recent advances in hypertension in sub-Saharan Africa. Heart. 2013;303227(19):1-8.

38. Nshisso LD, Reese A, Gelaye B, Lemma S, Berhane Y, Williams MA. Prevalence of hypertension and diabetes among Ethiopian adults. Diabetes Metab Syndr. 2012;6(1):36-41.

39. Tibazarwa K, Ntyintyane L, Sliwa K, et al. A time bomb of cardiovascular risk factors in South Africa: results from the heart of Soweto Study "Heart Awareness Days." Int J Cardiol. 2009;132(2): 233-239.

40. Maher D, Waswa L, Baisley K, Karabarinde A, Unwin N, Grosskurth H. Distribution of hyperglycaemia and related cardiovascular disease risk factors in low-income countries: a cross-sectional population-based survey in rural Uganda. Int J Epidemiol. 2011;40(1):160-171.

41. Onwuchekwa AC, Tobin-West C, Babatunde S. Prevalence and risk factors for stroke in an adult population in a rural community in the Niger Delta, South-South Nigeria. J Stroke Cerebrovasc Dis. 2014;23(3):505-510.

42. Guariguata L, Whiting DR, Hambleton I, Beagley J, Linnenkamp U, Shaw JE. Global estimates of diabetes prevalence for 2013 and projections for 2035. Diabetes Res Clin Pract. 2014;103(2): 137-149.

43. Katchunga P, Masumbuko B, Belma M, Kashongwe Munogolo Z, Hermans MP, M'Buyamba-Kabangu JR. Age and living in an urban environment are major determinants of diabetes among South Kivu Congolese adults. Diabetes Metab. 2012;38(4): 324-331.

44. Motala AA, Esterhuizen T, Gouws E, Pirie FJ, Mahomed AK. Diabetes and other disorders of glycemia in a rural South African community: prevalence and associated risk factors. Diabetes Care. 2008;31(9):1783-1788.

45. Mayega RW, Guwatudde D, Makumbi F, et al. Diabetes and pre-diabetes among persons aged 35 to 60 years in Eastern Uganda: prevalence and associated factors. PLoS One. 2013;8(8):e72554.

46. Ang YG, WU CX, Toh MP, Chia KS, Heng BH. Progression rate of newly diagnosed impaired fasting glycemia to type 2 diabetes mellitus: a study using the National Healthcare Group Diabetes Registry in Singapore. J Diabetes. 2012;4(2):159-163.

47. Heianza Y, Arase Y, Fujihara K, et al. Screening for pre-diabetes to predict future diabetes using various cut-off points for HbA1c and impaired fasting glucose: the Toranomon Hospital Health Management Center Study 4 (TOPICS 4). Diabet Med. 2012;29(9): e279-e285. 
48. Barr EL, Zimmet PZ, Welborn TA, et al. Risk of cardiovascular and all-cause mortality in individuals with diabetes mellitus, impaired fasting glucose, and impaired glucose tolerance: the Australian Diabetes, Obesity, and Lifestyle Study (AusDiab). Circulation. 2007;116(2): 151-157.

49. Ng M, Fleming T, Robinson M, et al. Global, regional, and national prevalence of overweight and obesity in children and adults during 1980-2013: a systematic analysis for the Global Burden of Disease Study 2013. Lancet. 2014;384(9945):766-781.
50. Rahmouni K, Correia ML, Haynes WG, MarkAL. Obesity-associated hypertension: new insights into mechanisms. Hypertension. 2005;45(1):9-14.

51. Ng M, Freeman MK, Fleming TD, et al. Smoking prevalence and cigarette consumption in 187 countries, 1980-2012. Jama. 2014;311(2):183-192.

52. Tran A, Gelaye B, Girma B, et al. Prevalence of metabolic syndrome among working adults in Ethiopia. Int J Hypertens. 2011;2011:193719.

53. Addo J, Smeeth L, Leon DA. Smoking patterns in Ghanaian civil servants: changes over three decades. Int J Environ Res Public Health. 2009;6(1):200-208.
Vascular Health and Risk Management

\section{Publish your work in this journal}

Vascular Health and Risk Management is an international, peerreviewed journal of therapeutics and risk management, focusing on concise rapid reporting of clinical studies on the processes involved in the maintenance of vascular health; the monitoring, prevention and treatment of vascular disease and its sequelae; and the involvement of

\section{Dovepress}

metabolic disorders, particularly diabetes. This journal is indexed on PubMed Central and MedLine. The manuscript management system is completely online and includes a very quick and fair peer-review system, which is all easy to use. Visit http://www.dovepress.com/ testimonials.php to read real quotes from published authors.

Submit your manuscript here: https://www.dovepress.com/vascular-health-and-risk-management-journal 